\title{
Titanium dioxide nanoparticle-protein interaction explained by docking approach
}

This article was published in the following Dove Press journal:

International Journal of Nanomedicine

\author{
Shivendu Ranjan ${ }^{1, *}$ \\ Nandita Dasguptal,* \\ Chinnappan Sudandiradoss ${ }^{2}$ \\ Chidambaram Ramalingam ' \\ Ashtosh Kumar ${ }^{3}$ \\ 'Industrial Biotechnology Division, \\ ${ }^{2}$ Division of Bioinformatics, School \\ of Bio Sciences and Technology, \\ VIT University, Vellore, Tamil Nadu, \\ ${ }^{3}$ Institute of Life Sciences, School of \\ Science and Technology, Ahemdabad \\ University, Ahemdabad, Gujarat, India \\ *These authors contributed equally \\ to this work
}

\begin{abstract}
Titanium dioxide has been proven for toxicity by in vitro and in vivo approaches, however, further studies are needed in nano-toxicological research using in silico analysis. In this study, Autodock 4.0.5 was used in an attempt to evaluate the interaction of titanium dioxide with proteins. Different cellular proteins were sorted to study the interaction, binding sites, and active sites as a pocket. These pockets have been determined using CastP - an online server. The analysis for the docked structures was performed with regard to the most efficient binding with amino acids. This study is the first of its kind to report on the in silico docking interaction of titanium dioxide nanoparticles without any surface modification. The higher negative binding energy shows strong binding of titanium dioxide with proteins. A strong interaction with different cellular proteins was observed, and more specifically, titanium dioxide nanoparticles showed frequent interaction with proline, lysine, as well as leusine.
\end{abstract}

Keywords: docking, titanium dioxide nanoparticle, interaction, CASTp

\section{Introduction}

Titanium dioxide has been widely used in consumer products, mainly food and cosmetics industry. Although bulk titanium dioxide is considered as safe, there are reports wherein these particles are converted into nano form in the processing steps. Titanium dioxide nanoparticles (TNPs) are now detected in the consumer products without any information about their shape, size or intention. The deliberate use of bulk titanium dioxide has exposed TNPs also to human body and environment. This exposure is undetected at various stages - synthesis (laboratory), manufacture (industry), use (consumer products, devices, medicines, etc) and through environmental exposure (through disposal). A lot of studies are in process about the genotoxic and carcinogenic potential of TNP. However, the classical toxicology methods are not applicable to TNPs as the shape and size greatly depends upon the synthesis method and the unique physicochemical properties of the TNPs. Thus, there is a need to develop an in silico approach that can validate the data observed from the in vitro and in vivo experiments. ${ }^{1,2}$ Docking provides a quick and convenient method to predict the interaction of cellular proteins with nanoparticles to predict toxicity. In this work, we have docked the TNP with several cellular proteins and tried to predict the TNP-protein interaction.

\section{Materials and methods Protein data bank file of proteins and TNP}

The protein data bank file of TNP was downloaded from the source file of University of Sydney website ${ }^{3}$ and for proteins Research Collaboratory For Structural Bioinformatics protein data bank. ${ }^{4}$ This has been summarized in Table 1. 
Table I Docking results of TNP-proteins interaction

\begin{tabular}{|c|c|c|c|c|c|c|c|c|}
\hline & PDB ID & $\begin{array}{l}\text { Binding } \\
\text { energy }\end{array}$ & KI & $\begin{array}{l}\text { Intermolecular } \\
\text { energy }\end{array}$ & $\begin{array}{l}\text { Internal } \\
\text { energy }\end{array}$ & $\begin{array}{l}\text { Torsional } \\
\text { energy }\end{array}$ & $\begin{array}{l}\text { Unbound } \\
\text { extended energy }\end{array}$ & $\begin{array}{l}\text { Ref } \\
\text { RMS }\end{array}$ \\
\hline ICAM-I & IP53 & -11.63 & $2.97 \mathrm{nM}$ & -12.73 & -2.88 & 1.1 & -2.88 & 171.59 \\
\hline CCL-20 & IM8A & -8.25 & $901.44 \mathrm{nM}$ & -9.34 & -2.75 & I.I & -2.75 & 39.68 \\
\hline COX-2 & $\begin{array}{l}\text { N/A (Bounded } \\
\text { PDB available) }\end{array}$ & & & & & & & \\
\hline IL-8 & IIL8 & -4.04 & $1.09 \mathrm{mM}$ & -5.14 & -2.66 & I.I & -2.66 & 11.57 \\
\hline NF-kB & ISVC & -8.29 & $841.35 \mathrm{nM}$ & -9.39 & -2.61 & I.I & -2.61 & 57.33 \\
\hline P-38 & $3 W 8 Q$ & -11.73 & $2.52 \mathrm{nM}$ & -12.83 & -2.49 & 1.1 & -2.49 & 35.13 \\
\hline PIGF & IFZV & -9.26 & $163.05 \mathrm{nM}$ & -10.36 & -2.77 & I.I & -2.77 & 41.37 \\
\hline CXCL-I & IMSG & 1.67 & $U / A$ & 0.57 & -2.96 & 1.1 & -2.95 & 13.62 \\
\hline CXCL-3 & $N / A$ & & & & & & & \\
\hline CXCL-5 & $2 M G S$ & 576.34 & $U / A$ & 575.34 & 42.18 & 1.1 & 42.18 & 8.93 \\
\hline CD 35 & IGKG & 5420 & $U / A$ & 5420 & 84.59 & 1.1 & 85.59 & 16.8 \\
\hline CD 66b & $N / A$ & & & & & & & \\
\hline MMP-9 & IL6] & -9.01 & $247.86 \mathrm{nM}$ & -10.11 & -2.72 & I.I & -2.72 & 63.94 \\
\hline
\end{tabular}

Abbreviations: CCL-20, chemokine ligand 20; CD, cluster of differentiation; COX-2, cyclooxygenase; IL-8, interleukin 8; CXCL, C-X-C motif chemokine ligand; ICAM-I, intercellular adhesion molecule I; MMP-9, matrix metallopeptidase 9; N/A, not applicable; NF-kB, nuclear factor kappa B; PIGF, placental growth factor; TNP, titanium dioxide nanoparticles; PDB, protein data bank; U/A, unassigned.

\section{Dimensions of TNP}

The dimensions of the lattice were derived from PyMol, and the size of the nanoparticle was identified. ${ }^{5}$

\section{Determination of binding site}

Computed atlas of surface topography of proteins (CASTp $)^{6}$ is used to visualize the annotated functional residues. The active sites of proteins have been predicted using CASTp. The best binding pockets with high area and volume were predicted by CASTp as active sites for each protein.

\section{Docking studies of TNP with proteins}

AutoDock 4.0 docking program was applied as discussed in our earlier published work. ${ }^{7}$

\section{A}

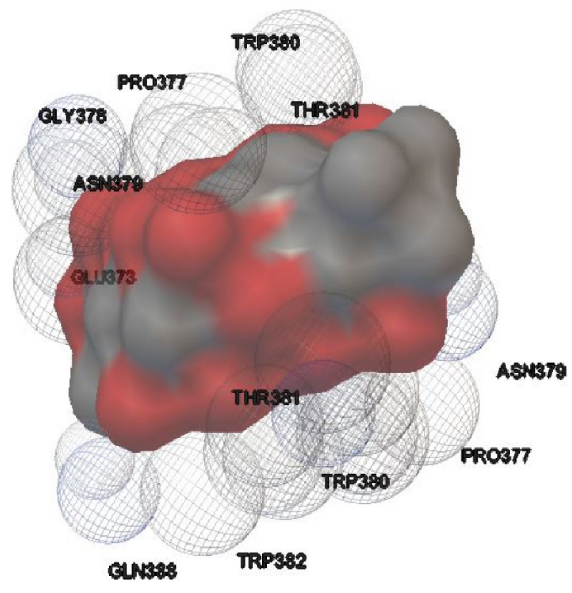

\section{Results and discussion}

The TNP size was determined as $1.09 \mathrm{~nm}$ using PyMol software. The efficient formation of protein-nanoparticle complexes was identified after observing the negative binding energy and intermolecular energy of TNP-protein complexes. The higher binding energy and intermolecular energy are -11.63 and -12.73 , respectively - for ICAM (intercellular adhesion molecule) titanium dioxide nanoparticle shows stable docked complex. Figure 1 depicts the hydrogen bond formed after docking. On the basis of the binding energy and intermolecular energy, it can be stated that ICAM and P-38 has stable binding with TNP, whereas no such complex formation takes place with CXCL-1 (C-X-C motif chemokine ligand), CXCL-5 and cluster of differentiation 35 . The binding

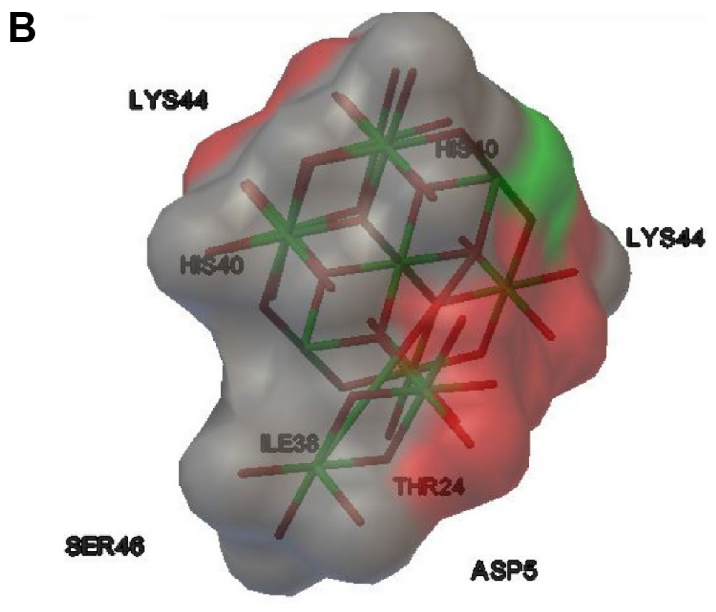

Figure I (Continued) 


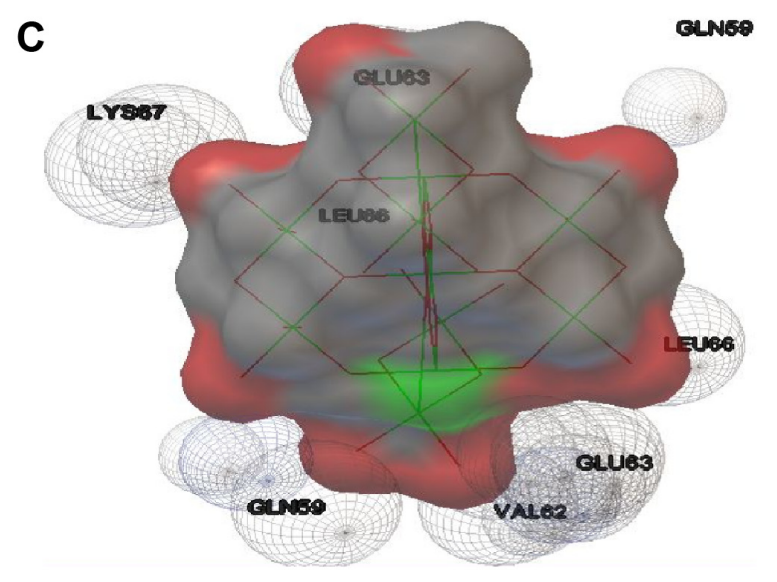

E

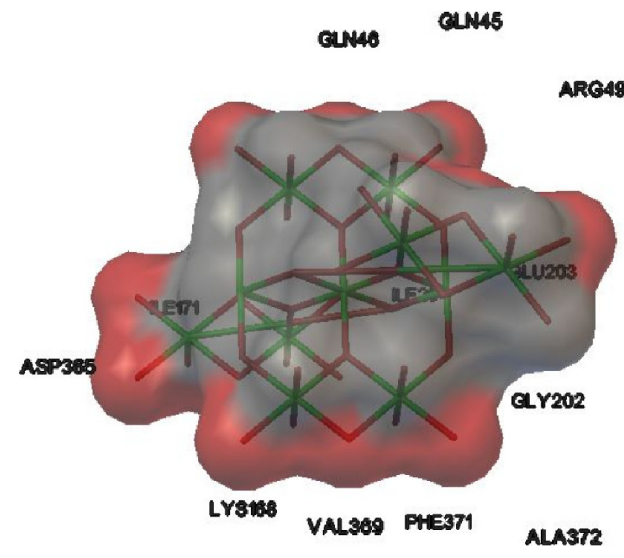

G

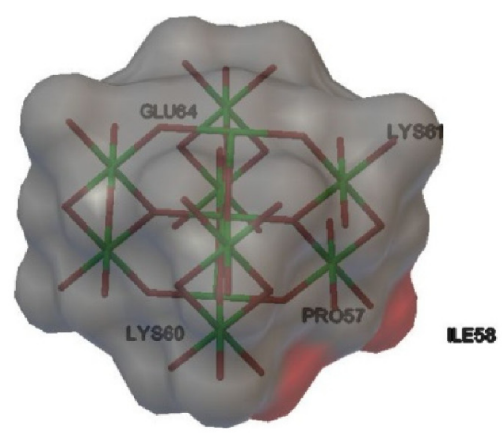

I

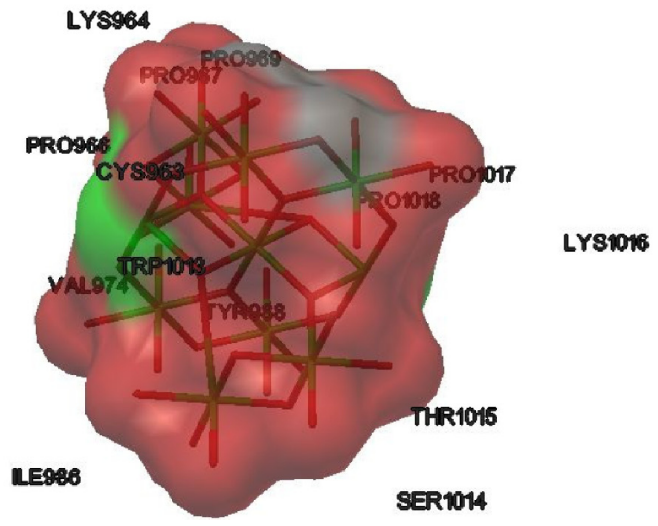

D

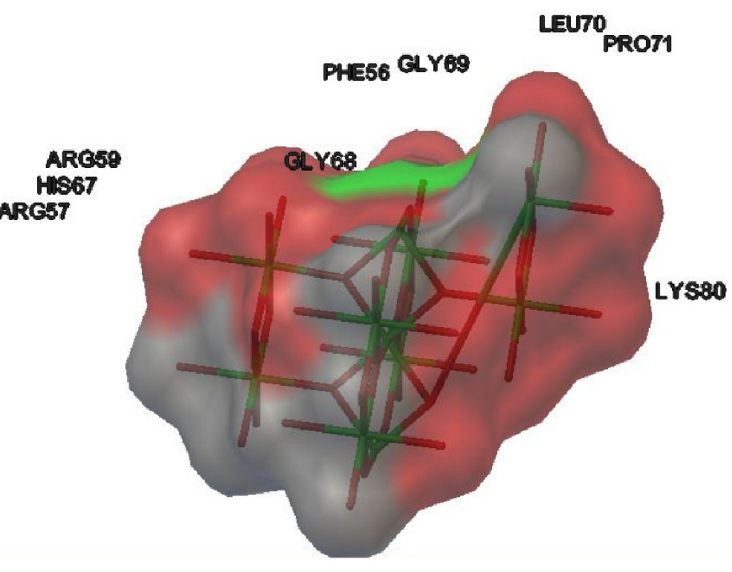

$\mathbf{F}$

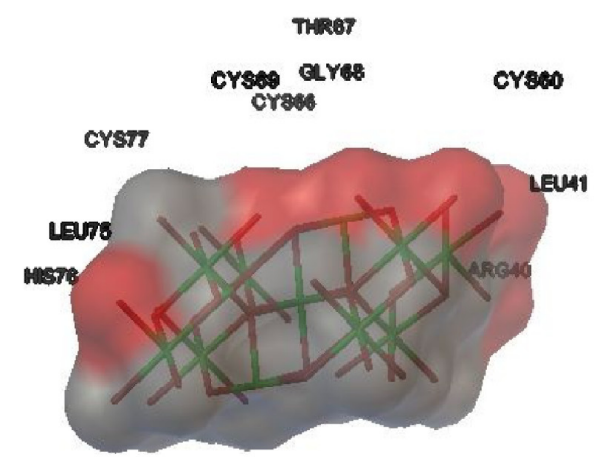

H

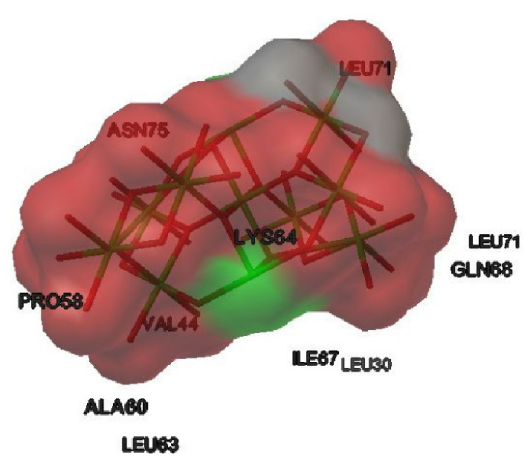

J

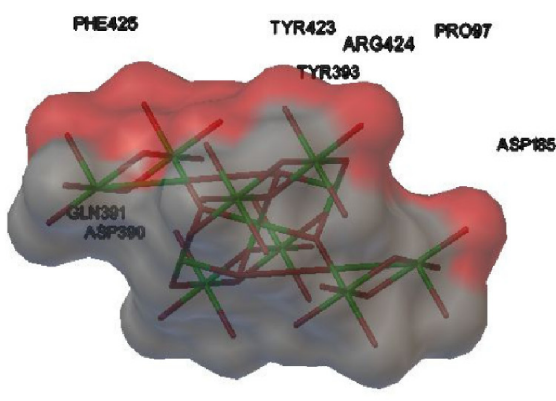

ARGOS

Figure I Interaction of TNP with (A) ICAM protein; (B) CCL-20 protein; (C) IL-8 protein; (D) NF-kB protein; (E) P-38 protein; (F) PIGF protein; (G) CXCL-I protein; (H) CXCL-5 protein; (I) CD-35 protein; (J) MMP-9 protein.

Abbreviations: CCL-20, chemokine ligand 20; CD-35, cluster of differentiation 35; CXCL-I, C-X-C motif chemokine ligand I; ICAM, intercellular adhesion molecule I; IL-8, interleukin 8; MMP-9, matrix metallopeptidase 9; NF-kB, nuclear factor kappa B; PIGF, placental growth factor; TNP, titanium dioxide nanoparticle. 
Table 2 Amino acid binding in the docked structure with different proteins

\begin{tabular}{|c|c|c|c|c|c|c|c|c|c|c|c|c|c|c|c|c|c|c|c|}
\hline & GLY & PRO & TRP & THR & ASN & GLU & GLN & LYS & SER & ASP & HIS & ILE & LEU & VAL & ARG & PHE & ALA & CYS & TYR \\
\hline ICAM-I & + & ++ & +++ & ++ & ++ & + & + & & & & & & & & & & & & \\
\hline CCL-20 & & & & + & & & & ++ & + & + & ++ & + & & & & & & & \\
\hline IL-8 & & & & & & ++ & ++ & + & & & & & ++ & + & & & & & \\
\hline$N F-k B$ & ++ & ++ & & & & & & + & & & + & & + & & ++ & + & & & \\
\hline P-38 & + & & & & & + & ++ & + & & + & & ++ & & + & ++ & + & + & & \\
\hline PIGF & + & & & + & & & & & & & + & & ++ & & + & & & ++++ & \\
\hline CXCL-I & & + & & & & + & & + & & & & + & & & & & & & \\
\hline CXCL-5 & & + & & & + & & + & + & & & & + & ++++ & + & & & + & & \\
\hline CD 35 & & +++++ & + & + & & & & ++ & + & & & + & & + & & & & + & + \\
\hline MMP-9 & & + & & & & & + & & & ++ & & & & & ++ & + & & & ++ \\
\hline Total frequency & 5 & 12 & 4 & 5 & 3 & 5 & 7 & 9 & 2 & 4 & 4 & 6 & 9 & 4 & 7 & 3 & 2 & 5 & 3 \\
\hline
\end{tabular}

Note: + , number of times TNP interacts with the respective amino acid.

Abbreviations: CCL-20, chemokine ligand 20; CD, cluster of differentiation 35; CXCL, C-X-C motif chemokine ligand; ICAM-I, intercellular adhesion molecule I; IL-8, interleukin 8; MMP-9, matrix metallopeptidase 9; NF-kB, nuclear factor kappa B; PIGF, placental growth factor; TNP, titanium dioxide nanoparticle.

and intermolecular energies along with torsion energy and the interacting amino acids have been tabulated (Table 1). Binding energy ranges from -11.63 to -4.04 for other proteins.

Analyzing the docking results, it can be concluded that TNP has frequent binding with positively charged R-group and nonpolar aliphatic R-groups amino acid containing amino acids of the proteins. More frequently, it binds with lysine and proline, and more interestingly, it does not bind with methionine. This suggests that hydrogen bond formation is prevented by the sulfur containing heavy chain R-group. Along with positively charged R-group and nonpolar aliphatic R-group amino acids, it also binds with aromatic R-group-, polar uncharged R-groups- and negatively charged R-group-containing amino acids, but the frequency of binding is very reduced in number as shown in Table 2. Least frequent binding has been observed with tyrosine, alanine, asparagine, serine and phenylalanine (Table 2). TNP has least affinity with aromatic R-group-containing amino acids, which may be attributed to the fact that TNP does not form a stable hydrogen bond because of the resonance energy stabilization of the amino acid.

\section{Acknowledgment}

Authors acknowledge Department of Biotechnology (DBT, India) for the funded project-BT/PR10414/PFN/20/961/2014.
Authors have presented this abstract in T-Nano 2014 at Ahmedabad University, Ahmedabad, Gujarat, India.

\section{Disclosure}

The authors report no conflicts of interest in this work.

\section{References}

1. Shukla RK, Kumar A, Vallabani NV, Pandey AK, Dhawan A. Titanium dioxide nanoparticle-induced oxidative stress triggers DNA damage and hepatic injury in mice. Nanomedicine. 2014;9(9):1423-1434.

2. Ranjan S, Dasgupta N, Chakraborty AR, et al. Nanoscience and nanotechnologies in food industries: opportunities and research trends. J Nanopart Res. 2014;16(6):2464.

3. University of Sydney $\mathrm{TiO}_{2}$.pdb 19-May-2007; 2014. Available from: http://firstyear.chem.usyd.edu.au/jmol/. Accessed April 10, 2014.

4. Research Collaboratory For Structural Bioinformatics Protein Data Bank; 2014. Available from: http://www.rcsb.org/pdb/home/home.do. Accessed April 25, 2014.

5. TPMGS. 2014. ThePyMOL Molecular Graphics System, (Version 1.5.0.4) Schrödinger, LLC.

6. Dundas J, Ouyang Z, Tseng J, Binkowski A, Turpaz Y, Liang J. CASTp: computed atlas of surface topography of proteins with structural and topographical mapping of functionally annotated residues. Nucl Acids Res. 2006;34:W116-W118.

7. Ranjan S, Dasgupta N, Chinnappan S, Ramalingam C, Kumar A. A novel approach to evaluate titanium dioxide nanoparticle-protein interaction through docking: an insight into mechanism of action. Proc Natl Acad Sci India Sect B Biol Sci. In press 2015.
International Journal of Nanomedicine

\section{Publish your work in this journal}

The International Journal of Nanomedicine is an international, peerreviewed journal focusing on the application of nanotechnology in diagnostics, therapeutics, and drug delivery systems throughout the biomedical field. This journal is indexed on PubMed Central, MedLine, CAS, SciSearch ${ }^{\circledR}$, Current Contents ${ }^{\circledR} /$ Clinical Medicine,

\section{Dovepress}

Journal Citation Reports/Science Edition, EMBase, Scopus and the Elsevier Bibliographic databases. The manuscript management system is completely online and includes a very quick and fair peer-review system, which is all easy to use. Visit http://www.dovepress.com/ testimonials.php to read real quotes from published authors. 